\title{
Fertilization of pig eggs in vivo and in vitro
}

\author{
R. H. F. Hunter \\ Centre de recherche en reproduction animale (C.R.R.A.), Faculté de médecine vétérinaire, \\ Université de Montréal, C.P. 5000, Saint-Hyacinthe, Québec, Canada J2S 7 C6
}

Keywords: gametes; capacitation; polyspermy; oviduct; embryo; pig

\section{Introduction}

The objective of this review is to set some of the problems associated with attempted in-vitro fertilization of pig eggs in a perspective drawn from the results of studies in live animals. Accordingly, the first part of the paper summarizes a variety of classical and more recent experiments performed in vivo whilst the second part examines in-vitro observations and the nature of the experimental conditions imposed. A more general discussion follows in which suggestions are made for future work.

It should be emphasized that this review does not attempt an exhaustive citation of relevant publications. None the less, it is hoped that sufficient references are given to provide access to the main body of literature available up to December 1988. Taken in conjunction with previous reviews having a different orientation (Hancock, 1962; Alanko, 1973; Baker \& Polge, 1976; Polge, 1978; Einarsson, 1980; Hunter, 1982), a majority of studies bearing on the process of fertilization in pigs should become accessible.

\section{In-vivo observations}

\section{Ovulation and egg transport}

The fimbriated extremities of the oviducts completely surround the ovaries at ovulation. Eggs are released from the collapsing follicles in a substantial investment of granulosa cells, together with viscous follicular fluid measuring as much as $0.35-0.4 \mathrm{ml}$ per follicle in gilts. Although this fluid enters the infundibulum, the direction of oviduct fluid flow (bulk flow) at this time is ad-ovarian and the follicular fluid is thought to be displaced into the peritoneal cavity. In gonadotrophin-primed prepubertal gilts, less than $1 \%$ by volume of follicular fluid passed down the oviduct towards the isthmus (Hansen et al., 1988).

Individual eggs within their follicular cell investment are propelled across the densely ciliated surface of the infundibulum and aggregate in the ampulla to form a cumulus plug (Hancock, 1961). In this condition, they are transported to the site of fertilization at the ampullary-isthmic junction in 30-45 min or less (Hunter, 1974). Although the cumulus plug persists for some hours in unmated animals, it is rapidly dispersed in those that have mated before ovulation and lingering follicular cells are seldom attached to the zona pellucida later than $6 \mathrm{~h}$ after ovulation (Szollosi \& Hunter, 1973).

In the normal situation of spontaneous cyclic ovulation, eggs are released from the ovaries as secondary oocytes (Spalding et al., 1955), with a prominent perivitelline space and conspicuous first polar body. Shedding of primary oocytes is an extremely rare event (Hancock, 1961).

Although oviduct fluid is the physiological medium for fertilization and early embryonic development, there have been few studies of such fluids in pigs. Iritani et al. (1974) recorded accumulation rates of $6.3 \mathrm{ml} / 24 \mathrm{~h}$ during oestrus falling to $2 \cdot 1 \mathrm{ml} / 24 \mathrm{~h}$ in the luteal phase. The volume of oviduct fluid was highest on the second day of oestrus around the time of ovulation. 
Biochemical studies of the fluid are extremely limited. Engle et al. (1968) examined the amino acid composition, but it was Iritani et al. (1974) who first emphasized that glycine is the predominant amino acid.

\section{Fertilization}

Studies on the process of fertilization in domestic pigs were undertaken 30 years ago, amongst which should be mentioned the works of Pitkjanen (1955), Thibault (1959) and Hancock (1959, 1961). These were closely followed by the experiments of C. Polge \& M. C. Chang (see Polge, 1978) which have not been published in full. Using phase-contrast microscopy of whole-mount preparations, Polge \& Chang gained a clear insight into the stages of sperm penetration, pronuclear formation, and the first two cleavage divisions. A timetable of these developmental stages, in eggs recovered from a second group of animals with known mating schedules, led to retrospective estimates of the time of ovulation: this was found to be $39-40 \mathrm{~h}$ after the onset of spontaneous oestrus. Other studies of pig eggs in Polge's laboratory at this time included those on primary oocytes released in response to gonadotrophin injection after a treatment for synchronization of oestrus. Such eggs frequently showed extensive polyspermy and failure of the sperm heads to evolve into male pronuclei (Polge \& Dziuk, 1965). Subsequent reports on the failure of sperm head evolution after in-vitro maturation and attempted fertilization often overlook this key observation, and the related suggestion by Dziuk \& Dickmann (1965) that the block to polyspermy develops concomitantly with meiotic maturation of the oocyte.

Experimental situations that might influence the efficiency of fertilization were also studied during the 1960s. They included examination of eggs released after superovulation (Hunter, 1964, 1966; Longenecker et al., 1965), eggs undergoing a phase of post-ovulatory ageing (Hunter, 1967a), and eggs from ovulations induced during the luteal phase of the oestrous cycle (Hunter, 1967b) or in post-partum sows (Hancock \& Buttle, 1968). Polyspermic fertilization was noted in many of these situations, suggesting that this abnormality was caused by changes in oviduct fluid composition under the influence of increasing ovarian progesterone secretion (Hunter, 1967b). However, there is still no specific evidence that components of oviduct fluid act to regulate the incidence of polyspermy.

Later in this phase of experimental work, the thesis of Alanko (1973) summarized fertilization and embryonic development in pigs under conditions of artificial insemination. The bearing of insemination techniques themselves on fertilization had been comprehensively studied by Baker $e t$ al. (1968), especially with reference to the influence of numbers and concentration of spermatozoa on the normality of fertilization. As proposed earlier by Hancock \& Hovell (1961), Baker et al. (1968) concluded that the concentration of spermatozoa in the ejaculate or inseminate had an important effect on the incidence of fertilization. Transport of live versus dead spermatozoa was examined by First et al. (1968a, b) and Baker \& Degen (1972), whilst the role of seminal plasma in the female tract was pursued by Einarsson \& Viring (1973) and Einarsson et al. (1980).

Timetables of the different stages of fertilization (Hunter, 1972a) and early embryonic development (Hunter, 1974) provide reference points for other experimental studies.

\section{Capacitation}

The involvement of capacitation in the preliminaries to fertilization in pigs first received comment from Thibault (1959) and Hancock (1961), with the observation that the 5-5-6-h interval between mating and fertilization represented a necessary delay, perhaps including a period of capacitation. More specific experiments were performed by C. Polge \& M. C. Chang (see Polge, 1978), involving surgical insemination of small aliquants of ejaculated semen directly into the oviduct ampulla shortly after ovulation. Once again, the conclusion was reached that capacitation of boar 
spermatozoa required a period of 5-6 h (Polge, 1978). In some conflict with these views, however, were the results of Hunter \& Dziuk (1968) in which animals were inseminated intra-cervically so that the eggs would be approximately $0,4,8$ or $12 \mathrm{~h}$ old at the time of sperm penetration. In this experimental situation, penetration of the zona pellucida by ejaculated spermatozoa was found within $2 \mathrm{~h}$ of insemination, and penetration of the vitellus with resumption of the second meiotic division within $3 \mathrm{~h}$ of insemination. Hence, capacitation after a peri-ovulatory insemination could occur twice as fast as previously thought. Satisfactory explanations for this apparent divergence of results followed in the early 1970 s, when it was discovered that the uterus and oviducts acted synergistically to accelerate the process of capacitation (Hunter \& Hall, 1974a), primarily by the removal of seminal plasma from spermatozoa swimming through the complex utero-tubal junction. Cell-free seminal plasma, derived from the same boar as was used for mating, deposited in $0 \cdot 02-0 \cdot 1 \mathrm{ml}$ volumes directly into the oviduct isthmus delayed fertilization by $2 \mathrm{~h}$ or more (Hunter \& Hall, 1974a).

The observation that pig eggs transplanted to the uterus show a very low incidence of fertilization, or none at all if oviduct fluids are prevented from reaching the uterus (Baker \& Polge, 1973), may be related to the requirement for boar spermatozoa to be exposed sequentially to the uterus and then the oviduct for completion of sapacitation.

Focussing on the origin of seminal plasma constituents and their regulatory role in the process of fertilization, later studies showed that suspensions of epididymal spermatozoa deposited directly into the oviducts varied in the time required for capacitation according to their region of origin along the epididymal duct (Hunter et al., 1976). In particular, sperm suspensions prepared from the upper corpus region could fertilize eggs $2 \mathrm{~h}$ sooner than those prepared from the cauda epididymidis of the same boar (Hunter et al., 1978). Moreover, cell-free seminal plasma prepared from the cauda epididymidis added to a suspension of spermatozoa from the upper corpus epididymidis of the same animal acted to delay fertilization by 1-2 h (Hunter et al., 1978). These observations therefore correspond with the traditional idea of stabilizing factors in seminal plasma being acquired in the epididymal duct which must then be neutralized or removed in the female tract before spermatozoa can become fully capacitated.

\section{Functional sperm reservoirs}

A related line of study has involved the rate of transport and site of storage of the fertilizing population of spermatozoa in the female tract. Sufficient spermatozoa to fertilize, in due course, a proportion of the eggs have already entered the oviducts within 15-30 min of completion of mating (Hunter \& Hall, 1974b; Hunter, 1981), a figure that contrasts strikingly with the rate of sperm transport in ruminants. It should be recalled, however, that ejaculation is almost directly into the uterus in pigs. A sperm suspension usually containing $1-2 \times 10^{8}$ cells $/ \mathrm{ml}$ can therefore bathe the utero-tubal junction by the completion of mating (Mann et al., 1956). The fact that a vanguard of spermatozoa can negotiate this junction to enter the oviducts within $15 \mathrm{~min}$ should not therefore cause surprise. However, the subsequent distribution of viable spermatozoa in relation to the time of ovulation is remarkable, not least in view of the $26-28 \mathrm{~cm}$ length of oviduct in these animals.

In an extensive study involving placement of ligatures at various intervals after mating at the onset of oestrus, and therefore progressively closer to the time of ovulation, coupled with a subsequent examination of the eggs for fertilization, it became apparent that the fertilizing population of spermatozoa was arrested in the caudal $1-2 \mathrm{~cm}$ of the oviduct isthmus until ovulation was imminent (Table 1). This region was therefore interpreted as the functional sperm reservoir (Hunter, 1984), rather than the utero-tubal junction as highlighted in the studies of du Mesnil du Buisson \& Dauzier (1955) and Rigby (1966). In fact, spermatozoa on the uterine side of the utero-tubal junction would remain vulnerable to the extensive post-coital invasion of polymorphonuclear leucocytes (Lovell \& Getty, 1968), suggesting that this would not be an appropriate location for prolonged sperm storage. 
Table 1. The influence of transecting the oviduct isthmus of pigs $1.5-2.0 \mathrm{~cm}$ proximal to the uterotubal junction at increasing intervals after mating at the onset of oestrus on the proportion of eggs subsequently fertilized ( 6 animals/group). (Modified from Hunter, 1984)

\begin{tabular}{|c|c|c|c|c|c|c|c|}
\hline \multirow{2}{*}{$\begin{array}{l}\text { Interval from } \\
\text { mating to } \\
\text { transection } \\
\text { (h) }\end{array}$} & \multirow[b]{2}{*}{$\begin{array}{l}\text { Condition of } \\
\text { ovaries at } \\
\text { transection }\end{array}$} & \multicolumn{3}{|c|}{ Transected isthmus } & \multicolumn{3}{|c|}{ Control isthmus* } \\
\hline & & $\begin{array}{l}\text { Eggs } \\
\text { recovered }\end{array}$ & $\begin{array}{l}\text { No. of } \\
\text { eggs } \\
\text { fertilized }\end{array}$ & $(\%)$ & $\begin{array}{l}\text { Eggs } \\
\text { recovered }\end{array}$ & $\begin{array}{l}\text { No. of } \\
\text { eggs } \\
\text { fertilized }\end{array}$ & $(\%)$ \\
\hline 3 & Preovulatory & 34 & 0 & (0) & 32 & 32 & $(100)$ \\
\hline 6 & Preovulatory & 40 & 0 & (0) & 35 & 33 & (94) \\
\hline 12 & Preovulatory & 42 & 0 & (0) & 41 & 41 & (100) \\
\hline 24 & Preovulatory & 50 & 0 & (0) & 41 & 39 & $(95)$ \\
\hline 30 & Preovulatory & 53 & 0 & (0) & 33 & 32 & (97) \\
\hline 36 & Preovulatory & 51 & 1 & (2) & 41 & 41 & (100) \\
\hline 38 & Preovulatory & 39 & 2 & $(5 \cdot 1)$ & 49 & 49 & $(100)$ \\
\hline 40 & Preovulatory & 48 & 19 & $(39 \cdot 6)$ & 35 & 35 & (100) \\
\hline $42-44$ & Postovulatory & 46 & 46 & (100) & 34 & 34 & (100) \\
\hline Total & & 403 & 68 & $(16.9)$ & 341 & 336 & $(98 \cdot 5)$ \\
\hline
\end{tabular}

*Double ligatures were placed around the control oviduct and then removed.

The caudal region of the oviduct isthmus acts to influence sperm cells in a conspicuous manner. Not only are boar spermatozoa largely trapped in this region for $36 \mathrm{~h}$ or more after mating at the onset of oestrus, but the motility of such spermatozoa is suppressed and the sperm surface remains intact as monitored by scanning electron microscopy (Fig. 1a); there is no indication of an acrosome reaction (Fléchon \& Hunter, 1981; Hunter et al., 1987). As the time of ovulation approaches, spermatozoa are released and become hyperactive with a whiplash pattern of flagellar beat. They proceed in finely-regulated numbers to the site of fertilization at the ampullary-isthmic junction, although this physical control of numbers is relaxed within $1-2 \mathrm{~h}$ of fertilization. Many spermatozoa are then able to confront the eggs, but such accessory spermatozoa arrive too late to cause abnormal forms of fertilization.

\section{Ovarian regulation of oviduct physiology}

The regulation of sperm storage, capacitation, hyperactivation and progression in the oviduct has been discussed extensively elsewhere (Hunter, 1987, 1988, 1989). In particular, a model has been proposed whereby the tubal epithelium transduces endocrine information from the preovulatory Graafian follicles (Fig. 2). In part, at least, this proposed means of hormonal regulation has a local countercurrent transfer basis from the ovarian vein to the oviduct branch of the ovarian artery (Hunter et al., 1983). Such a route would permit incisive programming of the oviduct epithelium, and indirectly thereby of sperm physiology (Fig. 2), by supplying higher concentrations of follicular hormones than would arrive by the systemic circulation. Temperature gradients between the two ends of the oviduct could also play an important role in regulating storage of spermatozoa and their subsequent activation (Hunter \& Nichol, 1986), and the temperature differentials also seem to be subject to ovarian endocrine regulation. An influence of viscous secretions has been considered essential to this phase of sperm storage, and substances such as the epididymal protein immobilin have been discussed (Hunter \& Nichol, 1986; Hunter et al., 1987). Underlying such interpretations is the observation that the pattern of follicular hormone secretion changes critically as ovulation approaches, enabling co-ordination of oocyte release with hyperactivation and redistribution of the male gametes.

\section{Ultrastructural observations}

Apart from the scanning electron microscopy studies referred to above (Fléchon \& Hunter, 1981; Hunter et al., 1987) and those of Stalheim et al. (1975) and Wu et al. (1976), there have 

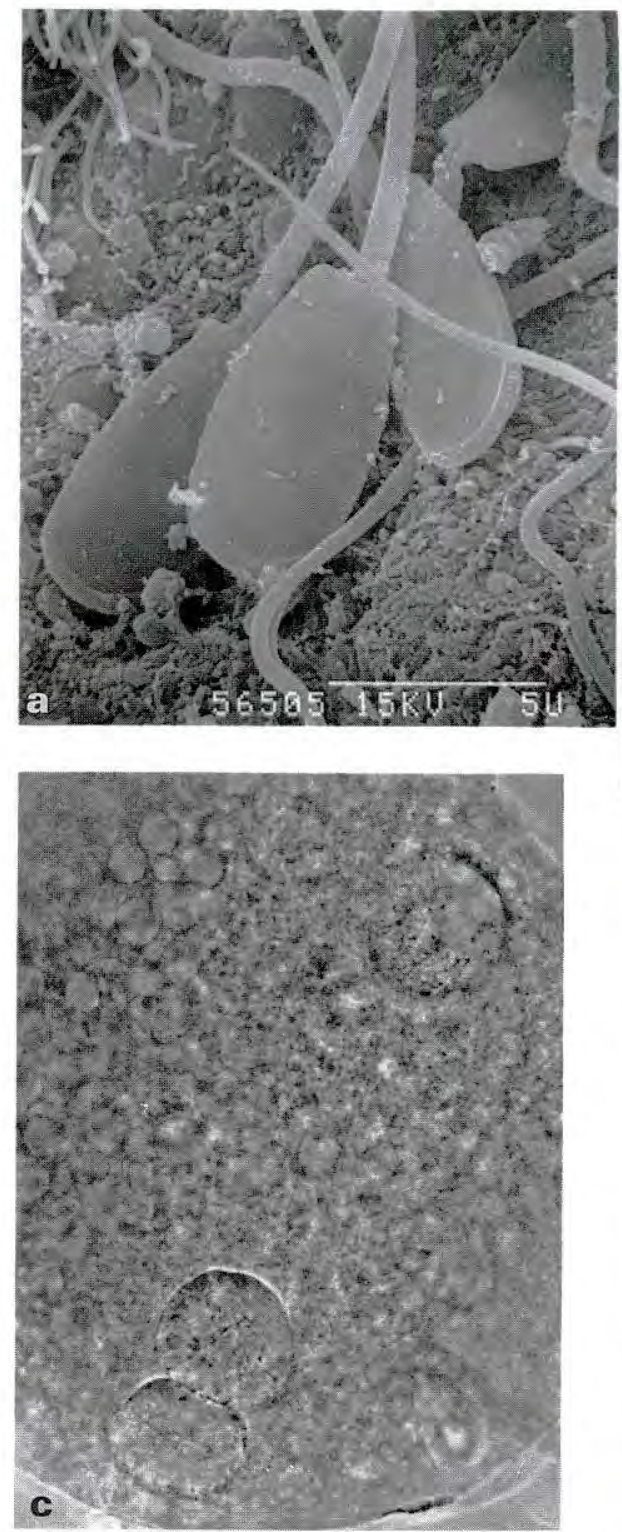
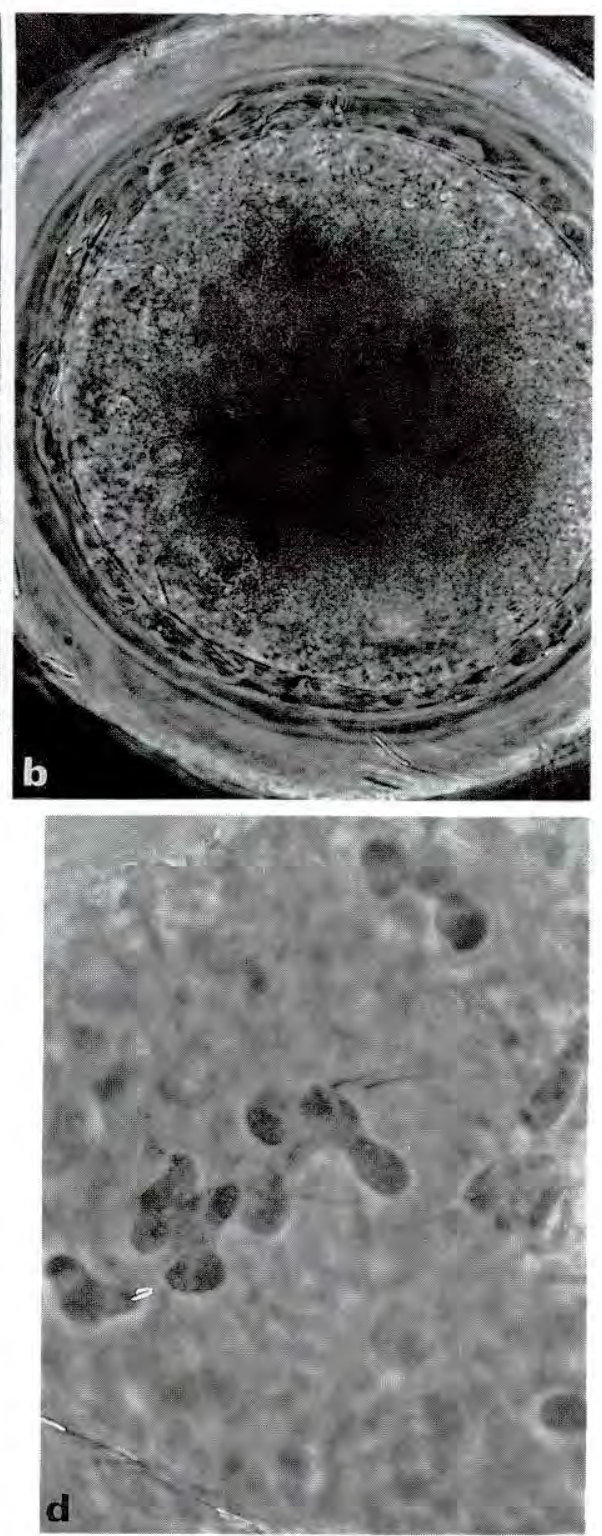

Fig. 1. Condition of pig gametes or zygotes examined under experimental conditions shortly before or after the time of ovulation. (a) Ejaculated boar spermatozoa viewed in the caudal portion of the oviduct isthmus. In this preovulatory storage site for fertilizing spermatozoa, the cells are still intact with no suggestion of an acrosome reaction or loss of sperm head membranes. Adapted from Hunter et al. (1987). (b) Whole-mount preparation of recently-ovulated pig egg showing large numbers of spermatozoa in the perivitelline space, together with spermatozoa in the substance of the zona pellucida. The morphology of the cytoplasm suggests the occurrence of a cortical reaction, yet the disposition of the perivitelline spermatozoa, with no obvious attachment to the plasmalemma, indicates that pig eggs can establish a vitelline block to polyspermy as well as a zona reaction. See Hunter \& Nichol (1988). (c) Phase-contrast view of a fixed and stained whole mount. The egg is dispermic, showing the female and a single male pronucleus uniting in one hemisphere of the egg, and an accessory male pronucleus in the opposite hemisphere. The location of the pronuclei is characteristic of this condition in pig eggs. (d) Phase-contrast view of a highly polyspermic pig egg in which coalescing sperm heads have formed chromatin aggregates. Although the mid-pieces have separated, there is little evidence of progressive nuclear decondensation and pronuclear formation in a majority of instances. (a) $\times 4500$; (b) $\times 500$; (c) $\times 650$; (d) $\times 550$. 


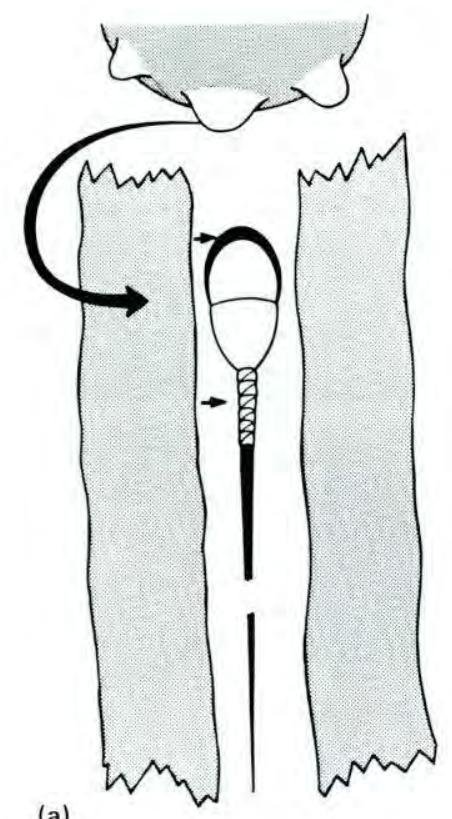

(a)

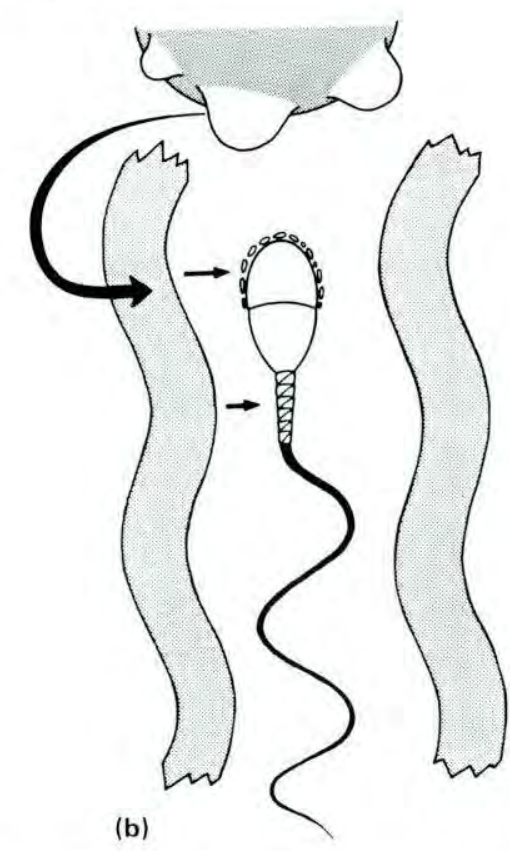

Fig. 2. Model to illustrate the manner whereby the endocrine activity of pre- or peri-ovulatory Graafian follicles acts locally to programme the membrane configuration and motility of spermatozoa in the lumen of the oviduct isthmus. Gonadal hormones (from the follicles) act on the oviduct epithelium whose transudates and secretions in turn influence the nature of the luminal fluids. Expression of capacitation is reasoned to be a peri-ovulatory event, at least in the large farm species with a protracted interval between the gonadotrophin surge and ovulation (Hunter, 1987). (a) Intact, relatively quiescent spermatozoon under the overall influence of preovulatory follicles. Membrane vesiculation on the anterior part of the sperm head is suppressed, as is the development of whiplash activity in the flagellum - presumably due to local molecular control mechanisms. The lumen of the oviduct isthmus is extremely narrow and contains viscous secretions, and myosalpingeal contractions are reduced. (b) An acrosomereacted, hyperactive spermatozoon under the influence of Graafian follicles on the point of ovulation. The oviduct isthmus has become more patent, enabling expression of the whiplash pattern of flagellar beat. Progression of such spermatozoa to the site of fertilization is also aided by enhanced contractile activity of the myosalpinx.

also been specific transmission electron microscope studies of fertilization in pig eggs. Notable amongst findings here was the absence of a true acrosome reaction until spermatozoa were actually penetrating between cells of the corona radiata or in contact with the surface of the zona pellucida (Szollosi \& Hunter, 1978). Thus arose the suggestion that capacitated boar spermatozoa may be especially sensitive to some factor associated with or emanating from the egg coats, this factor acting to promote the membrane vesiculation characteristic of the acrosome reaction (see Barros et al., 1967). In addition was the observation that the acrosome of boar spermatozoa swells and liberates free acrosomal contents whilst the plasma and outer acrosomal membranes are still apparently intact.

Observations on the functional state of the cortical granules are also relevant to the second part of this paper for, although a classical cortical granule reaction occurs under conditions of fertilization in vivo (Szollosi, 1967; Szollosi \& Hunter, 1973), this reaction may be incomplete in vitro, especially after procedures of culture for inducing oocyte maturation (see Cran \& Cheng, 1986). Such evidence for membranous incompetence may be an important factor underlying the elevated concentrations of polyspermy frequently reported in vitro. 


\section{Polyspermic penetration}

In this summary of fertilization in vivo, it may be instructive to reconsider observations on polyspermy. Polyspermic penetration of the vitellus is a pathological condition in mammals (Beatty, 1957), and polyploid embryos usually die at a very early stage of development (BomselHelmreich, 1961). Although, as mentioned above, studies involving post-ovulatory insemination or insemination during the luteal phase of the oestrous cycle suggested that the high incidence of polyspermy might be a consequence of altered oviduct biochemistry, this is no longer accepted. On the other hand, diverse experiments have indicated that polyspermy of pig eggs in vivo is primarily due to abnormally high numbers of competent spermatozoa reaching the egg surface more or less simultaneously. Multiple sperm penetration through the zona pellucida (Fig. Ib) and into the vitellus (Figs 1c and d) may therefore occur before the block to polyspermy has become fully established.

Experimental models in support of this view of polyspermy include: (i) surgical insemination directly into the oviducts (Polge et al., 1970; Hunter, 1973a, b; Polge, 1978); (ii) resection of the oviduct isthmus to remove the sperm gradient imposed by this portion of the tract (Hunter \& Léglise, 1971); (iii) reducing the oedematous condition and muscular contraction of the utero-tubal junction and caudal isthmus, once more removing the sperm gradient, by local microinjection of a solution of progesterone under the serosal layer (Hunter, 1972b) or by large doses of a progesterone solution given systemically (Day \& Polge, 1968).

A finding that may prove to be of special significance was that the incidence of polyspermy in most of these studies was between 20 and $35 \%$ (Table 2). Because such figures correspond closely to the extent of embryonic mortality recorded in 'Western' breeds of pig, susceptibility to polyspermy under experimental conditions may be a means of revealing incompetent or subnormal oocytes (Hunter, 1979). This remark is restricted to the in-vivo situation. There is no reason to suppose that the repeated observation of polyspermy in vitro (see below) necessarily reflects culture of an enhanced population of incompetent oocytes.

Table 2. The incidence of polyspermic fertilization exhibited in mature pigs in various experimental situations after mating or insemination at the time of oestrus (after Hunter, 1979)

\begin{tabular}{|c|c|c|c|c|}
\hline \multirow[b]{2}{*}{ Treatment } & \multirow{2}{*}{$\begin{array}{c}\text { No. of } \\
\text { eggs } \\
\text { examined }\end{array}$} & \multicolumn{2}{|c|}{$\begin{array}{c}\text { Polyspermic } \\
\text { eggs }\end{array}$} & \multirow[b]{2}{*}{ Reference } \\
\hline & & No. & $\%$ & \\
\hline Delayed mating & 53 & 6 & $11 \cdot 0^{*}$ & Thibault (1959) \\
\hline Delayed mating & 41 & 12 & $29 \cdot 2$ & Hancock (1959) \\
\hline Delayed insemination & 149 & 23 & $15 \cdot 4$ & Hunter (1967a) \\
\hline Tubal surgery & 34 & 11 & $32 \cdot 4$ & Hunter \& Léglise (1971) \\
\hline Progesterone micro-injections & 198 & 64 & $32 \cdot 3$ & Hunter $(1972 b)$ \\
\hline Tubal insemination & 77 & 26 & $33 \cdot 8$ & Hunter (1973a) \\
\hline
\end{tabular}

*A further $21 \%$ of eggs were considered digynic, giving a total of $32 \%$.

The polyspermic condition itself has been used to examine the spatial disposition and fate of accessory male elements in the vitellus (Hunter, 1973a) and the formation of chromatin aggregates between adjoining sperm heads that have failed to decondense (Hunter, 1976; Fig. 1d). The incidence of polyspermy under specific conditions of surgical insemination has also been used to monitor the capacitating potential of individual oviducts in relation to the time of ovulation (Hunter \& Nichol, 1988).

\section{Zona composition and sperm penetration}

Gametes of the domestic pig have been much used in recent years in two areas of research bearing directly on fertilization, both areas having a strong biochemical orientation. One concerns 
the composition of the zona pellucida (Dunbar, 1983), and the nature of its sperm binding sites (Gwatkin et al., 1980). The other has focussed on the spectrum of acrosomal enzymes and their role in penetration of the egg investments (e.g. Brown \& Cheng, 1985; Jones et al., 1988).

The zona pellucida is known to be a chemically complex, acellular glycoprotein matrix, the surface of which is highly irregular (Fig. 3). Although some form of sperm-head binding is considered as the initial step in the species-specific penetration of this matrix, the surface of the zona may also act purely physically to arrest a motile spermatozoon. If so, then other more specific forms of contact interaction might seem unnecessary for penetration to proceed. Moreover, the distinction between contact, binding, and penetration by the highly motile fertilizing spermatozoon is not obvious, for these events represent a continuum.

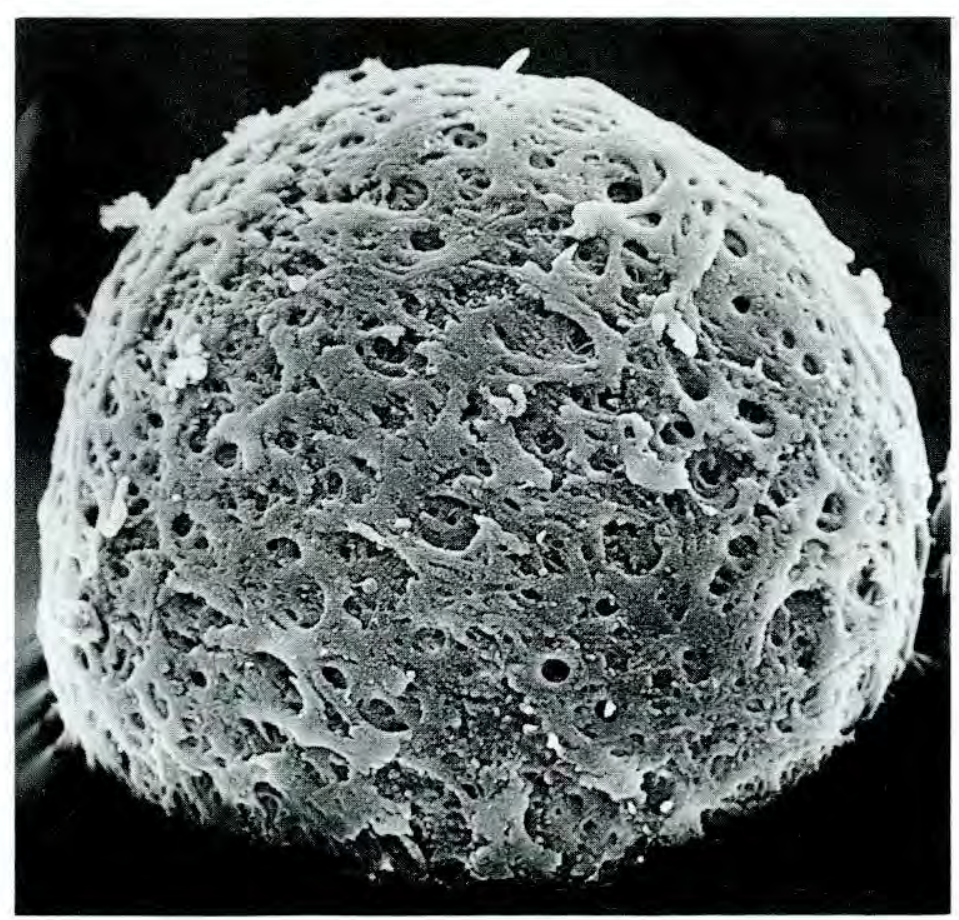

Fig. 3. A scanning electron micrograph of a pig egg denuded of granulosa cells to show the uneven, loose and spongy outer surface of the zona pellucida. Such a surface may facilitate initial contact reactions with the highly motile fertilizing spermatozoon and with subsequent accessory spermatozoa. $\times 950$. (Courtesy of Dr J. E. Fléchon).

Despite characterization of the pig zona pellucida in several laboratories, the zona glycoprotein composition may be altered after ovulation. Brown \& Cheng (1986) reported that significant amounts of pig oviducal glycoproteins were able to bind firmly to the zona, even in the presence of the cumulus oophorus. The secretory activity of the cumulus cells themselves should not be overlooked, for there is ultrastructural evidence for a continued deposition of material on the surface of the zona after ovulation.

As to the role of the boar sperm protease, acrosin, in the process of zona penetration, the evidence remains equivocal. Working with freshly-ovulated pig eggs, Brown \& Cheng (1985) reported that such acrosin had asserted only a limited and selective proteolysis, a view they maintained in a later publication (Brown \& Cheng, 1986). On the other hand, boar sperm proacrosin, the zymogen form of the protease, was able to recognize and bind to carbohydrate moieties 
of zona pellucida glycoproteins (Jones et al., 1988), suggesting an important function in the determinants of species specificity. Even so, the focus should not remain simply on acrosin, for other lytic enzymes may contribute actively to penetration of the zona pellucida.

\section{In-vitro observations}

The purpose of this section is to discuss attempts to obtain not only fertilization in vitro but also successful embryonic development following transplantation of penetrated eggs. Previous reviews dealing with the subject in farm animals include those of Baker \& Polge (1976), Betteridge (1977), Hunter (1980, 1988), Wright \& Bondioli (1981), Brackett \& Bousquet (1984) and First \& Parrish (1987).

\section{Unpublished work}

As an introduction to experiments specifically on pigs, reference will be made to the author's unpublished studies of 1968-1970 whilst working in the laboratory of Professor C. Thibault at Jouy-en-Josas, France. Although these experiments were unsuccessful, some of the observations may none the less be instructive.

Approximately 70 separate trials were conducted, each involving a minimum of 8 oocytes, more commonly 12-17. The time of ovulation was controlled in donor Large White gilts by an injection of $500 \mathrm{i} . \mathrm{u}$. hCG given in late pro-oestrus. Ovulation occurred $43-44 \mathrm{~h}$ after the injection, signifrcantly later than observed in comparable animals elsewhere (Hunter, 1972c). Animals were killed in the abattoir adjoining the laboratory within $1-2 \mathrm{~h}$ of ovulation, and the reproductive tract brought to the culture room $\left(30^{\circ} \mathrm{C}\right)$ in warm, sterile, surgical drapes no later than 3-4 min after stunning. In most trials, eggs were recovered in cumulus by flushing the oviducts with $5-10 \mathrm{ml}$ medium at $37^{\circ} \mathrm{C}$. Media used for flushing and subsequent culture included TC 199, Tyrode's solution and Brinster's medium, supplemented with bovine serum albumin or fetal calf serum and antibiotics. Osmolality varied from 290 to 310 mosmols. The $\mathrm{pH}$ was adjusted to $7 \cdot 6$, and maintained under a gas phase of $5 \% \mathrm{CO}_{2}$ and $95 \%$ air.

Ejaculated and epididymal (upper corpus or cauda) sperm suspensions were tested, and also spermatozoa recovered from the oviduct isthmus $6-8 \mathrm{~h}$ after mating at the onset of oestrus. Ejaculated and epididymal samples were subjected to mild centrifugation procedures for washing and, on occasions, also to preincubation with or without explants of oviduct ampullary epithelium in an attempt to achieve capacitation. Although progressive motility was usually good in the freshly-prepared and washed samples, hyperactive (whiplash) motility was not observed. Moreover, motility was invariably poor after a $2-3 \mathrm{~h}$ preincubation period, although sometimes improved in the presence of preovulatory follicular fluid.

The in-vitro fertilization system used in most experiments consisted of $0.1 \mathrm{ml}$ microdrops under equilibrated oil in Falcon plastic Petri dishes. However, rotating glass tubes containing the culture medium were also tried (Dauzier el al., 1954) and, as a third method, a semi-in-vitro system was prepared. This consisted of the whole oviduct dissected free from its ligaments, and suspended vertically by the fimbria in oxygenated medium in a glass tube. Rhythmic contractile activity continued for several hours. The preparation was made immediately after slaughter within $1 \mathrm{~h}$ of ovulation, and the eggs were left undisturbed. Sperm suspensions were introduced into the caudal isthmus.

All eggs in these experiments were subsequently fixed, stained, and sectioned histologically at 8-10 $\mu \mathrm{m}$. Although one or more nuclei were noted from time to time, there was never evidence of sperm penetration into or through the zona pellucida. However, there was a strong impression from the large numbers of spermatozoa still associated with the surface of the zona, after rinsing and fixing, that some form of attachment had begun. The principal conclusion in these studies was 
that inadequate sperm motility underlay the failure to obtain fertilization. A means of maintaining and/or stimulating excellent progressive motility in culture was not discovered. Irreversible damage of the gametes was not evident, for transplantation of the microdrop contents (eggs and spermatozoa) into the oviducts of oestrous recipients after $5-6 \mathrm{~h}$ of culture permitted fertilization and cleavage to the 2 - or 4 -celled stage.

\section{Further lack of success}

Baker \& Polge (1976) also recorded unsuccessful attempts at in-vitro fertilization of pig eggs. Using 280 in-vivo matured oocytes with expanded cumulus obtained $1-3 \mathrm{~h}$ before ovulation, and 267 oocytes obtained from the oviducts $1-4 \mathrm{~h}$ after ovulation, they noted large numbers of spermatozoa attached to the zona pellucida but none had penetrated through to the vitellus. Sperm suspensions had been prepared from the sperm-rich fraction of the ejaculate, from surgicallyrecovered epididymal secretions or from different portions of the reproductive tract of oestrous gilts. Various cuiture media were examined, with or without the addition of follicular or oviduct fluid. Transplantation of droplets containing the mixture of gametes into the oviducts of oestrous animals after $4 \mathrm{~h}$ of incubation in vitro yielded only $33 \%$ of penetrated eggs. Furthermore, the recovered eggs showed conspicuous degeneration of the cytoplasm (Baker \& Polge, 1976), an observation of some relevance to the outcome of subsequent transplant studies (see below).

\section{Sperm penetration of eggs in vitro}

Apart from isolated instances of in-vitro fertilization of pig eggs (e.g. Harms \& Smidt, 1970), significant progress in producing a workable system for generating viable embryos was not reported until the studies of Cheng (1985) and Cheng et al. (1986). However, two preceding studies deserve comment. In a quite extensive series, Iritani (1978) recorded low proportions of penetrated oocytes (3-26\%) after in-vitro maturation of primary oocytes aspirated from Graafian follicles of 2-3 mm diameter. In an attempt to achieve capacitation, ejaculated or cauda epididymal spermatozoa had been preincubated in a post-mortem preparation of oviduct and uterine tissue. Development of the penetrated oocytes was not tested. Nagai et al. (1984) also used cultured follicular oocytes and reacted these with washed, preincubated samples of epididymal or ejaculated spermatozoa. Low concentrations of epididymal spermatozoa during preincubation gave a low incidence of penetration $(11 \%)$ whereas a high preincubation concentration gave a high incidence of penetration $(71-75 \%)$ but arrested development of penetrated eggs due to polyspermy. No fertilization was obtained with ejaculated spermatozoa (Table 3).

Zona-free preparations of pig eggs will not be discussed in this review. Although they have proved valuable for studying sperm-egg interactions (Pavlok, 1981), there is no evidence that they could yield viable embryos.

Details of the methodology used in these earlier trials, and in more recent experiments, are summarized in Table 3. As will be noted, most groups did not test the viability of eggs fertilized in vitro by subsequent transplantation studies. In fact, by the end of 1988, only 3 groups had reported production of live piglets after procedures of in-vitro fertilization. Litter size was small on each occasion.

The system reported by Cheng (1985) and Cheng et al. (1986) contained important new features: (i) freshly-ejaculated spermatozoa were preincubated for $4 \mathrm{~h}$ at $37^{\circ} \mathrm{C}$ at $\mathrm{pH} 7.8$ in medium TC 199 supplemented with fetal calf serum, sodium pyruvate and calcium lactate; (ii) the preincubated spermatozoa were then cultured with ovulated oocytes at $39^{\circ} \mathrm{C}$ for $6-8 \mathrm{~h}$ with $4.7 \mathrm{~mm}$ calcium, leading to $89 \%$ of penetrated eggs. Although it is not clear how they were identified (i.e. selected), monospermic eggs cultured in modified BMOC-2 medium (modified Brinster's) for $40 \mathrm{~h}$ yielded $86 \%$ of $2-4$-cell embryos. Transfer of 206 embryos at the 2-4-cell stage to 15 recipient 
gilts gave 6 pregnancies and 19 piglets born. Whilst these results have provided encouragement, it remains important to question why the overall yield of viable fetuses $(11 \%)$ was not higher.

\section{Why such poor viability of in-vitro fertilized embryos?}

The answer to this question presumably lies in a divergence from physiological conditions during the procedures of gamete recovery and preparation in vitro, and likewise during the steps of actual in-vitro fertilization and culture of the newly-formed zygotes. The paragraphs that follow involve speculation. If the shortcomings in the in-vitro system were clearly understood, then these could be modified and a significant improvement in results might be obtained.

Until recently, actually obtaining fertilization in vitro of pig eggs was the major problem, with the inference that, in the absence of polyspermy or digyny, the zygote was potentially viable. This view cannot be justified. There is ample evidence that damage to the gametes may not impede a successful union, yet the zygote may fail to develop normally and show derangements at an early stage. As an example, $X$-irradiation of ejaculated rabbit spermatozoa (20000 r) did not prevent them from competing successfully with non-irradiated spermatozoa from the same buck after insemination of the mixed sperm suspension. However, eggs fertilized by the irradiated spermatozoa showed a delayed first cleavage, and further embryonic development failed (Bedford \& Hunter, 1968). Whether this kind of failure usually corresponds closely with the onset of expression of the embryonic genome is yet to be resolved. More recent studies in rats also underline the influence of lesions in the gametes on early embryonic failure (Setchell et al., 1988).

For in-vitro fertilization of pig eggs, the question must therefore be asked whether preincubation of spermatozoa at elevated temperatures and/or in a hyperosmotic medium leads to subtle but irreversible damage to the nucleus which may not prevent fertilization but which acts to compromise normal development. The same question must be asked of any pretreatment of oocytes, and likewise of the in-vitro fertilization system itself. For example, exposure of the gametes to incubation temperatures of $39^{\circ} \mathrm{C}$ may be more traumatic than hitherto realized and, in the case of the oocyte, perhaps damaging not only to the nucleus but also to the cytoplasmic organelles. Cheng et al. (1986) emphasized that the relatively high level of calcium (4.7 mm) was essential for inducing capacitation of boar spermatozoa in vitro and likewise for successful fertilization. None the less, the delayed cleavage reported for in-vitro generated pig embryos by Yoshida (1987) might be an expression of nuclear and/or cytoplasmic damage. The delay is certainly significant when compared with the in-vivo situation, in which the first cleavage is found 14-16 h after sperm penetration and the second cleavage occurs approximately 6-8 h later (C. Polge \& M. C. Chang, unpublished; Hunter, 1974).

Quite apart from the preceding suggestions, other sources of potential damage could reside in laboratory methods used to date (Table 3). After collecting ovaries at the abattoir, subjecting them to temperature variations and anoxia en route to the laboratory, in due course extracting oocytes from follicles far smaller than the preovulatory diameter, and culturing them for various times in microdrop systems overburdened with cells, the fact that viable embryos cannot be generated at an incidence comparable with the in-vivo situation is not surprising. And what actually happens in the culture system? The notion that such systems are chemically defined is an illusion. The number of spermatozoa added is quite unphysiological, large numbers of cells will die, degradation products will be released into the medium, and its chemical composition will change significantly. And what is the gas tension at the base of a microdroplet under oil in a plastic Petri dish? $\ln$ vivo, the system within the oviducts is sensitive and dynamic with micro-currents, ciliary and muscular movements, and a constant adjustment of the medium. The epithelium and underlying vascular supply cannot be taken for granted, nor perhaps macromolecular secretions that interact with the surface of gametes and embryos.

So what is the way forward? A logical, if painstaking, means of testing these ideas would be to subject gametes to the in-vitro fertilization procedures favoured in recent studies, and then to 


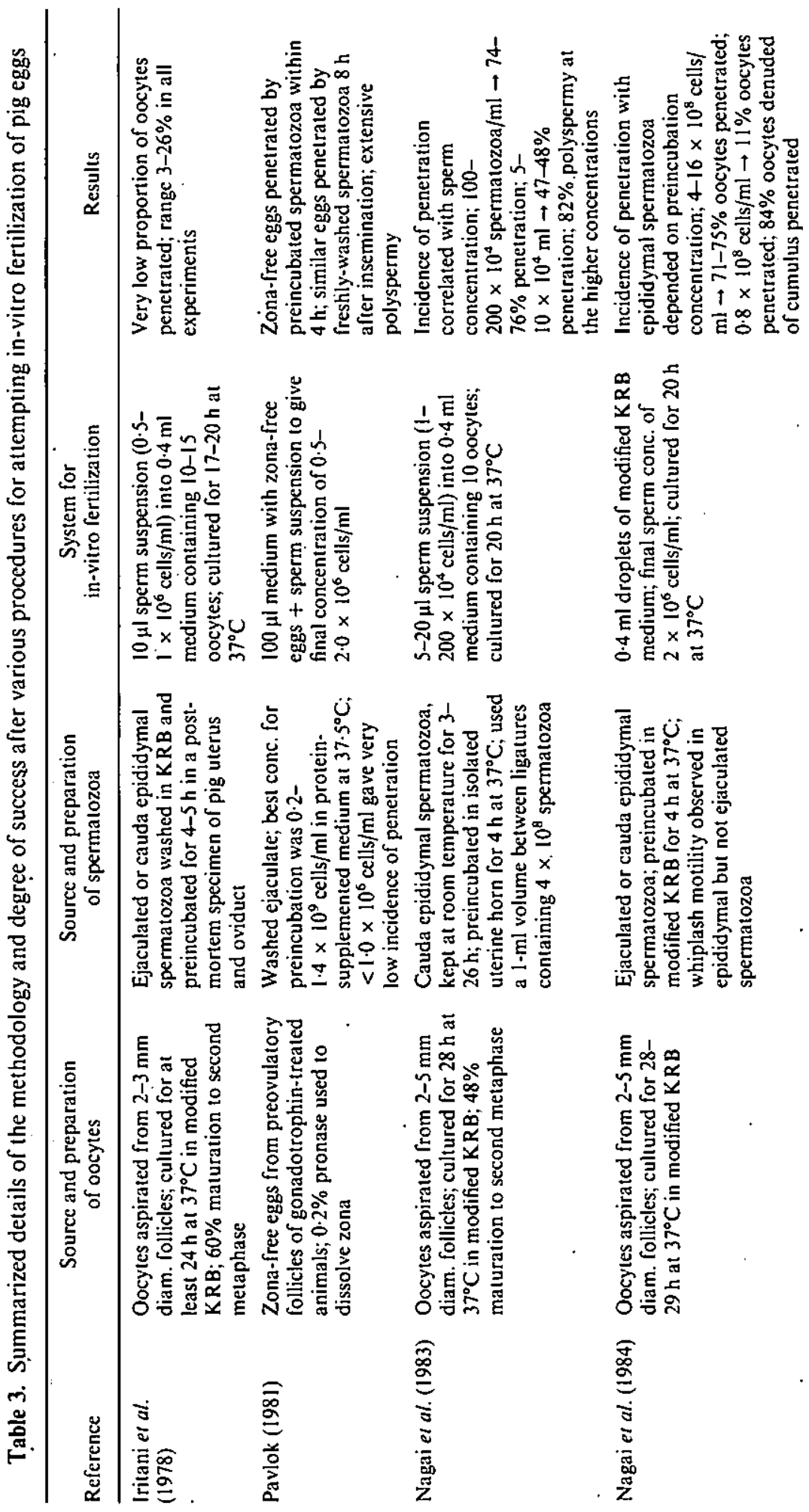




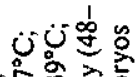

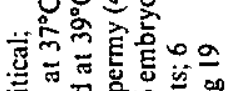

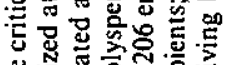

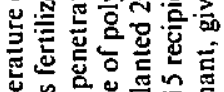

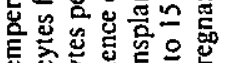
$\therefore$ 的落

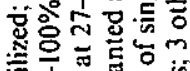

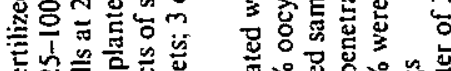
일

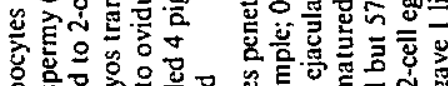

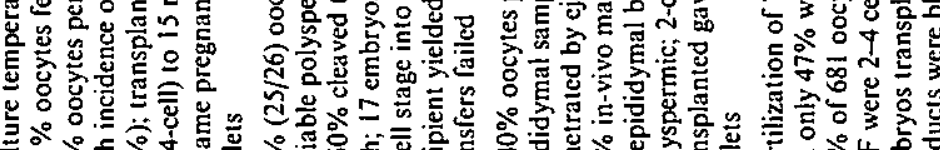

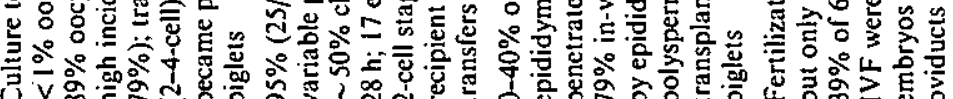

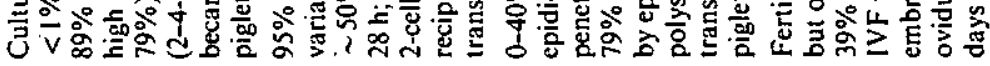
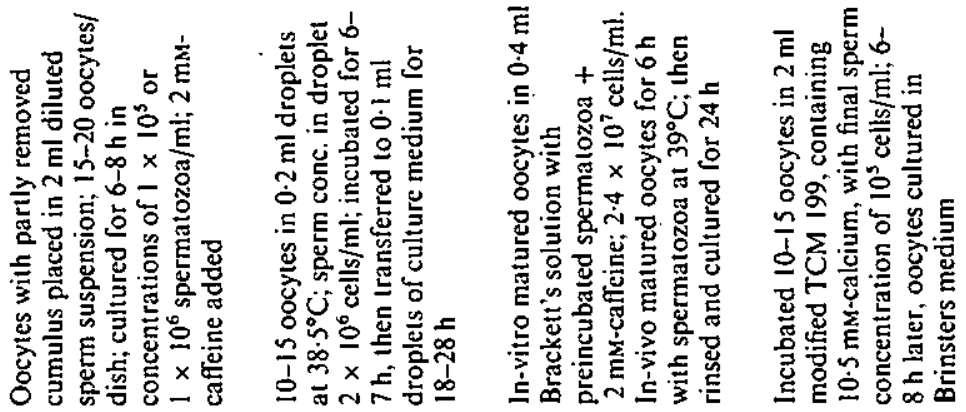

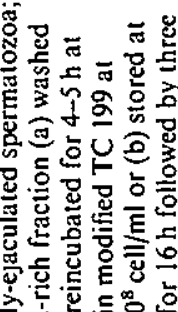

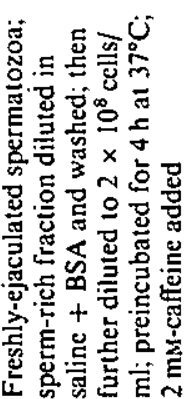

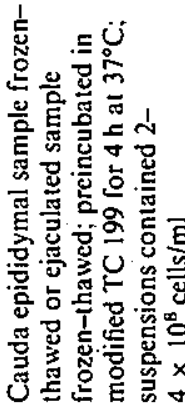

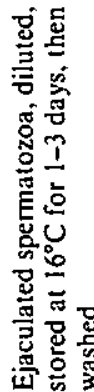

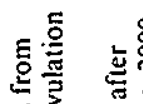

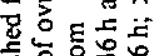

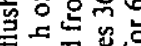

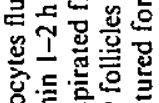

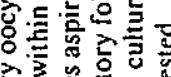

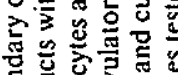

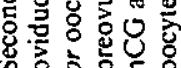

言焉部

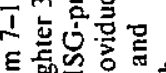

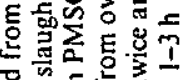

造

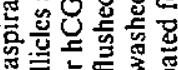

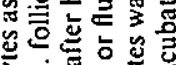

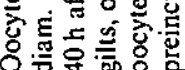

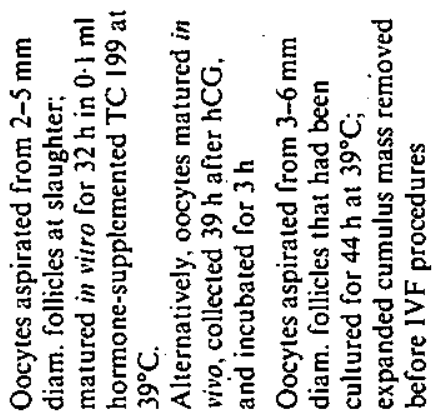

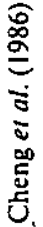

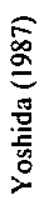

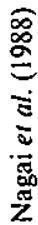

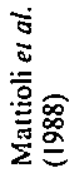


examine viability by transplanting the mixture of gametes to the oviducts close to the time of ovulation. If normal fertilization and embryonic development were not obtained, then a rigorous and stepwise analysis would have to be made of the in-vitro system. Of course, the ultimate reference point for what is and is not acceptable in vitro in terms of temperature, osmolarity, $\mathrm{pH}$ and actual composition of a culture medium would be the conditions within an oviduct shortly after ovulation. Unfortunately, not only are most of the relevant measurements not available for pigs, but the techniques for making them might lead to artefacts. None the less, in-vivo measurements of the above values using the best technology would be an advance, and would provide information of great relevance to successful in-vitro fertilization and embryonic development in culture. This Centre (the CRRA) is currently engaged on such a programme of research. The alternative approach of inspired modifications to techniques used in laboratory rodents might yield reasonable levels of success from time to time, but it is unlikely to be widely repeatable and therefore satisfactory in the long term.

Despite this point of view, an interim approach that might yield better results than those reported so far would be to work in vitro with oocytes in cumulus together with their bathing fluid aspirated from the site of fertilization shortly after ovulation (see above). The cell suspension would be set up as a microdrop preparation. Vigorous ejaculated or epididymal spermatozoa could be selected by means of washing and subsequent swim-up techniques. To reduce the risk of polyspermy, small numbers of highly motile spermatozoa would be introduced into the microdrops. After $4-5 \mathrm{~h}$ of initial interaction, the gamete or zygote preparation would be transplanted to fresh microdrops of post-ovulatory fluid obtained from the oviduct lumen at the ampullary-isthmic junction, together with explants of epithelium from the same region of the oviduct. The emphasis would therefore be on the microenvironment that is thought to play a vital role during fertilization in vivo.

I thank Sylvie Lagace and Frances Anderson for typing the manuscript; friends at the AFRC Institute of Animal Physiology and Genetics Research for copies of reprints; and the University of Edinburgh for the use of library facilities.

\section{References}

Alanko, M. (1973) Fertilisation and early development of ova in artificially-inseminated gilts. Doctoral thesis, University of Helsinki.

Baker, R.D. \& Degen, A. (1972) Transport of live and dead boar spermatozoa within the reproductive tract of gilts. J. Reprod. Fert. 28, 369-377.

Baker, R.D. \& Polge, C. (1973) Sperm penetration of pig eggs in utero. J. Reprod. Fers. 33, 347-350.

Baker, R.D. \& Polge, C. (1976) Fertilization in swine and cattle. Can. J. Anim. Sci. 56, 105-119.

Baker, R.D., Dziuk, P.J. \& Norton, H.W. (1968) Effect of volume of semen, number of sperm and drugs on transport of sperm in artificially inseminated gilts. $J$. Anim. Sci. 27, 88-93.

Barros, C., Bedford, J.M., Franklin, L.E. \& Austin, C.R. (1967) Membrane vesiculation as a feature of the mammalian acrosome reaction. J. Cell. Biol. 34, C1-C5.

Beatty, R.A. (1957) Parthenogenesis and Polyploidy in Mammalian Developmen. Cambridge University Press.

Bedford, J.M. \& Hunter, R.H.F. (1968) The influence of $\mathrm{X}$-irradiation of rabbit spermatozoa on fertilization and early cleavage. J. Reprod. Fert. 17, 49-57.

Betteridge, K.J. (1977) Embryo Transfer in Farm
Animals. Monograph No. 16, Canada Department of Agriculture.

Bomsel-Helmreich, O. (1961) Hetcroploidie expérimentale chez la truie. Proc. $4 \mathrm{~h} \mathrm{~lm}$. Congr. Anim. Reprod. \& A.I., The Hague 3, 578-581.

Brackett, B.C. \& Bousquet, D. (1984) Comparative aspects of fertilization in vitro. In In Vitro Ferilization and Embryo Transfer, pp. 32-43. Eds A. Trounson \& C. Wood. Churchill-Livingstone, Edinburgh.

Brown, C.R. \& Cheng, W.T.K. (1985) Limited proteolysis of the porcine zona pellucida by homologous sperm acrosin. J. Reprod. Fert. 74, 257-260.

Brown, C.R. \& Cheng, W.T.K. (1986) Changes in composition of the porcine zona pellucida during development of the oocyte to the 2- to 4-cell embryo. $J$. Embryol. exp. Morph. 92, 183-191.

Cheng, W.T.K. (1985) In vitro fertilization of farm animal oocytes. Ph.D. thesis, C.N.A.A.

Cheng, W.T.K., Polge, C. \& Moor, R.M. (1986) In vitro fertilization of pig and sheep oocytes. Theriogenology 25, 146, abstr.

Cran, D.G. \& Cheng, W.T.K. (1986) The cortical reaction in pig oocytes during in vivo and in vitro fertilisation. Gamere Res. 13, 241-251.

Day, B.N. \& Polge, C. (1968) Effects of progesterone on 
fertilization and egg transport in the pig. $J$. Reprod. Fert. 17, 227-230.

Dauzier, L., Thibault, C. \& Wintenberger, S. (1954) La fécondation in vitro de l'oeuf de la lapine. $C . r$. hebd. Séanc. Acad. Sci., Paris 238, 844-845.

du Mesnil du Buisson, F. \& Dauzier, L. (1955) La remontée des spermatozoides du verrat dans le tractus de la truie en oestrus. C. r. Séanc. Soc. Biol. 149, 76-79.

Dunbar, B.S. (1983) Morphological, biochemical and immunochemical characterisation of the mammalian zona pellucida. In Mechanism and Control of Animal Ferrilization, pp. 139-175. Ed. J. F. Hartmann. Academic Press, New York.

Dziuk, P.J. \& Dickmann, Z. (1965) Failure of the zona reaction in five pig eggs. Nalure, Lond. 208, 502-503.

Einarsson, S. (1980) Site, transport and fate of inseminated semen. Proc. $9 \mathrm{th} \mathrm{Im}$. Congr. Anim. Reprod. \& A.I. Madrid 1, 147-158.

Einarsson, S. \& Viring, S. (1973) Effect of boar seminal plasma on the porcine uterus and the isthmus part of the oviducts in vitro. Acta vet. scand. 14, 639-641.

Einarsson, S., Jones, B., Larsson, K. \& Viring, S. (1980) Distribution of small- and medium-sized molecules within the genital tract of artificially inseminated gilts. J. Reprod. Fert. 59, 453-457.

Engle, C.C., Dunn, J.S., Hood, R.O., Williams, D.J., Foley, C.W. \& Trout, H.F. (1968) Amino acids in sow and rabbit oviduct fluids. J. Anim. Sci. 27, 1786, abstr.

First, N.L. \& Parrish, J.J. (1987) In-vitro fertilization of ruminants. J. Reprod. Fert., Suppl. 34, 151-165.

First, N.L., Short, R.E., Peters, J.B. \& Stratman, F.W. (1968a) Transport and loss of boar spermatozoa in the reproductive tract of the sow. J. Anim. Sci. 27, 1037-1040.

First, N.L., Short, R.E., Peters, J.B. \& Stratman, F.W. (1968b) Transport of boar spermatozoa in estrual and luteal sows. J. Anim. Sci. 27, 1032-1036.

Fléchon, J.E. \& Hunter, R.H.F. (1981) Distribution of spermatozoa in the utero-tubal junction and isthmus of pigs, and their relationship with the luminal epithelium after mating. Tissue \& Cell 13, 127-139.

Gwatkin, R.B.L., Anderson, O.F. \& Williams, D.T. (1980) Large scale isolation of bovine and pig zonae pellucidae: chemical, immunological and receptor properties. Gamete Res. 3, 217-231.

Hancock, J.L. (1959) Polyspermy of pig ova. Anim. Prod. 1, 103-106.

Hancock, J.L. (196I) Fertilization in the pig. J. Reprod. Ferl. 2, 307-331.

Hancock, J.L. (1962) Fertilization in farm animals. Anim. Breed. Abstr. 30, 285-310.

Hancock, J.L. \& Buttle, H.L. (1968) Tubal transport and fertilisation of ova in gonadotrophin-treated pigs. $J$. Reprod. Fert. 16, 261-270.

Hancock, J.L. \& Hovell, G.J.R. (196I) The effect of semen volume and number of spematozoa on the fertility of intra-uterine inseminations of pigs. Anim. Prod. 3, 153-161.

Hansen, C., Srikandakumar, A. \& Downey, B.R. (1988) The presence of follicular fluid in the oviduct and its contribution to the acrosome reaction. Proc. $6 \mathrm{th} \mathrm{Ann}$. Reproduction Research Colloque, McGill University, No. 4, pp. 3-4.

Harms, V.E. \& Smidt, D. (1970) In vitro fertilization of follicular and tubal eggs of swine. Tierärz. Wschr. 14, 269-275.

Hunter, R.H.F. (1964) Superovulation and fertility in the pig. Anim. Prod. 6, 189-194.

Hunter, R.H.F. (1966) The effect of superovulation on fertilization and embryonic survival in the pig. Anim. Prod. 8, 457-465.

Hunter, R.H.F. (1967a) The effects of delayed insemination on fertilization and early cleavage in the pig. $J$. Reprod. Fert. 13, 133-147.

Hunter, R.H.F. (1967b) Polyspermic fertilization in pigs during the luteal phase of the estrous cycle. $J$. exp. Zool. 165, 451-460.

Hunter, R.H.F. (1972a) Fertilization in the pig: sequence of nuclear and cytoplasmic events. $J$. Reprod. Fert. 29, 395-406.

Hunter, R.H.F. (1972b) Local action of progesterone leading to polyspermic fertilization in pigs. J. Reprod. Fert. 31, 433-444.

Hunter, R.H.F. (1972c) Ovulation in the pig: timing of the response to injection of human chorionic gonadotrophin. Res. vet. Sci. 13, 356-361.

Hunter, R.H.F. (1973a) Polyspermic fertilization in pigs after tubal deposition of excessive numbers of spermatozoa. J. exp. Zool. 183, 57-64.

Hunter, R.H.F. (1973b) Transport, migration and survival of spermatozoa in the female genital tract: species with intra-uterine deposition of semen. INSERM Colloq. 26, 309-342.

Hunter, R.H.F. (1974) Chronological and cytological details of fertilization and early embryonic development in the domestic pig, Sus scrofa. Anat. Rec. 178, 169-186.

Hunter, R.H.F. (1976) Sperm-egg interactions in the pig: monospermy, extensive polyspermy, and the formation of chromatin aggregates. J. Anat. 122, 43-59.

Hunter, R.H.F. (1979) Ovarian follicular responsiveness and oocyte quality after gonadotrophic stimulation of mature pigs Annls Biol. anim. Biochim. Biophys. 19, ISII-1520.

Hunter, R.H.F. (1980) Physiology and Technology of Reproduction in Female Domestic Animals. Academic Press, London.

Hunter, R.H.F. (1981) Sperm transport and reservoirs in the pig oviduct in relation to the time of ovulation. $J$. Reprod. Fert. 63, 109-117.

Hunter, R.H.F. (1982) Interrelationships between spermatozoa, the female reproductive tract, and the egg investments. In Control of Pig Reproduction, pp. 49-63. Eds D. J. A. Cole \& G. R. Foxcroft. Butterworths, London.

Hunter, R.H.F. (1984) Pre-ovulatory arrest and periovulatory redistribution of competent spermatozoa in the isthmus of the pig oviduct. J. Reprod. Fert. 72, 203-2Il.

Hunter, R.H.F. (1987) Peri-ovulatory physiology of the oviduct, with special reference to progression, storage, and capacitation of spermatozoa. In New Horizons in Sperm Cell Research, pp. 31-45. Ed. H. Mohri. Japan Sci. Soc. Press, Tokyo.

Hunter, R.H.F. (1988) The Fallopian Tubes: Their Role in Fertility and Infertility. Springer-Verlag, Berlin.

Hunter, R.H.F. (1989) Ovarian programming of gamete progression and maturation in the female genital tract. Zool. J. Linn. Soc. 95, 117-124. 
Hunter, R.H.F. \& Dziuk, P.J. (1968) Sperm penetration of pig eggs in relation to the timing of ovulation and insemination. J. Reprod. Fert. 15, 199-208.

Hunter, R.H.F. \& Hall, J.P. (1974a) Capacitation of boar spermatozoa: synergism between uterine and tubal environments. J. exp. Zool. 188, 203-214.

Hunter, R.H.F. \& Hall, J.P. (1974b) Capacitation of boar spermatozoa: the influence of post-coital separation of the uterus and Fallopian tubes. Anat. Rec. 180, 597-604.

Hunter, R.H.F. \& Léglise, P.C. (1971) Polyspermic fertilization following tubal surgery in pigs, with particular reference to the rolle of the isthmus. $J$. Reprod. Fert. 24, 233-246.

Hunter, R.H.F, \& Nichol, R. (1986) A preovulatory tcmperature gradient between the isthmus and ampulla of pig oviducts during the phase of sperm storage. J. Reprod. Fert. 77, 599-606.

Hunter, R.H.F. \& Nichol, R. (1988) Capacitation potential of the Fallopian tube: a study involving surgical insemination and the subsequent incidence of polyspermy. Gamete Res. 21, 255-266.

Hunter, R.H.F., Holtz, W. \& Henfrey, P.J. (1976) Epididymal function in the boar in relation to the fertilizing ability of spermatozoa. J. Reprod. Fert. 46, 463-466.

Hunter, R.H.F., Holtz, W. \& Herrmann, H. (1978) Stabilizing role of epididymal plasma in relation to the capacitation time of boar spermatozoa. Anim. Reprod. Sci. 1, 161-166.

Hunter, R.H.F., Cook, B. \& Poyser, N.L. (1983) Regulation of oviduct function in pigs by local transfer of ovarian steroids and prostaglandins: a mechanism to influence sperm transport. Europ. J. Obstet. Gynec. Reprod. Biol. 14, 225-232.

Hunter, R.H.F., Fléchon, B. \& Fléchon, J.E. (1987) Preand peri-ovulatory distribution of viable spermatozoa in the pig oviduct: a scanning electron microscope study. Tissue \& Cell 19, 423-436.

Iritani, A., Sato, E. \& Nishikawa, Y. (1974) Secretion rates and chemical composition of oviduct and uterine fluids in sows. J. Anim. Sci. 39, 582-588.

Iritani, A., Niwa, K. \& Imai, H. (1978) Sperm penetration in vivo of pig follicular oocytes matured in culture. $J$. Reprod. Fert. 54, 379-383.

Jones, R., Brown, C.R. \& Lancaster, R.T. (1988) Carbohydrate-binding properties of boar sperm proacrosin and assessment of its rôlc in sperm-egg recognition and adhesion during fertilization. Development 102 , $781-792$.

Longenecker, D.E., Lasley, J.F. \& Day, B.N. (1965) Fecundity in gilts and sows administered PMS. $J$. Anim. Sci. 24, 924, abstr.

Lovell, J.E. \& Getty, R. (1968) Fate of semen in the uterus of the sow: histologic study of endometrium during the 27 hours after natural service. $A m$. $J$. vet. Res. 29, 609-625.

Mann, T., Polge, C. \& Rowson, L.E.A. (1956) Participation of seminal plasma during the passage of spermatozoa in the female reproductive tract of the pig and horse. J. Endocr. 13, 133-140.

Mattioli, M., Bacci, M.L., Gateati, G. \& Seren, E. (1988) Developmental competence of pig oocytes matured and fertilized in vitro. Proc. $10 \mathrm{th} \mathrm{lm}$. Pig Vet. Soc. Rio de Janiero VII, p. 311 , abstr.
Nagai, T., Niwa, K., Jritani, A. \& Leidl, W. (1983) Improved rates of sperm penetration in vitro of pig follicular oocytes matured in culture. Jap. J. Fert. Steril. 28, 313-318.

Nagai, T., Niwa, K. \& Iritani, A. (1984) Effect of sperm concentration during preincubation in a defined medium on fertilization in vitro of pig follicular oocytes. J. Reprod. Ferr. 70, 27I-275.

Nagai, T., Takahashi, T., Masuda, H., Shioya, Y., Kuwayama, M., Fukushima, M., Iwasaki, S. \& Hanada, A. (1988) In-vitro fertilization of pig oocyles by frozen boar spermatozoa. $J$. Reprod. Ferı. 84, $585-591$.

Pavlok, A. (1981) Penetration of hamster and pig zonafree eggs by boar ejaculated spermatozoa preincubated in vitro. Int. J. Ferril. 26, 101-106.

Pitkjanen, I.G. (1955) Ovulation, fertilization and early embryonic development in the pig. Izv. Akad. Nauk SSSR, Ser. Biol. 3, 120-131.

Polge, C. (1978) Fertilization in the pig and horse. $J$. Reprod. Feri. 54, 46I-470.

Polge, C. \& Dziuk, P. (1965) Recovery of immature eggs penetrated by spermatozoa following induced ovulation in the pig. J. Reprod. Fert. 9, 357-358.

Polge, C., Salamon, S. \& Wilmut, I. (1970) Fertilizing capacity of frozen boar semen following surgical insemination. Vet. Rec. 87, 424-428.

Rigby, J.P. (1966) The persistence of spermatozoa at the utero-tubal junction of the sow. J. Reprod. Ferı. 11, I53-155.

Setchell, B.P., D'Occhio, M.J., Hall, M.J., Laurie, M.S., Tucker, M.J. \& Zupp, J.L. (1988) Is embryonic mortality increased in normal female rats mated to subfertile males? J. Reprod. Fert. 82, 567-574.

Spalding, J.F., Berry, R.O. \& Moffit, J.G. (1955) The maturation process of the ovum of swine during normal and induced ovulations. J. Anim. Sci. 14, 609-620.

Stalheim, O.H.V., Gallagher, J.E. \& Deyoe, B.L. (1975) Scanning electron microscopy of the bovine, porcine and caprine uterine tube (oviducl). Am. J. vet. Res. 36, 1069-1075.

Szollosi, D. (1967) Development of cortical granules and the cortical reaction in rat and hamster eggs. Anat. Rec. 159, 43!-446.

Szollosi, D. \& Hunter, R.H.F. (1973) Ultrastructural aspects of fertilization in the domestic pig: sperm penetration and pronucleus formation. J. Anat. 116, 181-206.

Szollosi, D. \& Hunter, R.H.F. (1978) The nature and occurrence of the acrosome reaction in spermatozoa of the domestic pig, Sus scrofa. J. Anat. 127, 33-41.

Thibault, C. (1959) Analyse de la fécondation de l'oeuf de la truic après accouplement ou insémination artificielle. Annls Zootech. 8, 165-177.

Wright, R.W. \& Bondioli, K.R. (1981) Aspects of in vitro fertilization and embryo culture in domestic animals. J. Anim. Sci. 53, 702-729.

Wu, A.S.H., Carlson, S.D. \& First, N.L. (1976) Scanning electron microscopic study of the porcine oviduct and uterus. J. Anim. Sci. 42, 804-809.

Yoshida, M. (1987) In vitro fertilization of pig oocytes matured in vivo. Japan J. vet. Sci. 49, 711-718. 